\title{
Proteomic analysis of the basic proteins in 5-fluorouracil resistance of human colon cancer cell line using the radical-free and highly reducing method of two-dimensional polyacrylamide gel electrophoresis
}

\author{
SATORU TANAKA $^{1}$, AKIKO SAKAI ${ }^{2}$, KOUSEI KIMURA ${ }^{1}$, HIDEJI YOSHIDA $^{3}$, HIDEO FUSHITANI $^{1}$, \\ AKIHITO OGATA ${ }^{1}$, AKIKO MIYAMOTO ${ }^{1}$, MASAKAZU FUKUSHIMA ${ }^{4}$, \\ AKIRA WADA $^{3,5}$ and NOBUHIKO TANIGAWA ${ }^{1}$ \\ Departments of ${ }^{1}$ General and Gastroenterological Surgery, ${ }^{2}$ Chemistry and ${ }^{3}$ Physics, Osaka Medical College, \\ Osaka, 2-7 Daigaku-machi, Takatsuki City, Osaka 569-8686; ${ }^{4}$ Tokushima Research Center, \\ Taiho Pharmaceutical Co., 224-2, Hiraishi-ebisuno, Kawauchi, Tokushima 771-0194; ${ }^{5}$ Yoshida \\ Biological Laboratory, 11-1 Takehanasotoda-cho, Yamashina-ku, Kyoto 607-8081, Japan
}

Received April 1, 2008; Accepted May 30, 2008

DOI: 10.3892/ijo_00000016

\begin{abstract}
Fluorouracil (5-FU) is widely used for the treatment of patients with advanced colon cancers and it is the mainstay of chemotherapy. However, the acquisition of resistance to 5-FU is one of the most prominent obstacles to successful chemotherapy. The purpose of this study was to identify the novel biological basis of 5-FU resistance in colon cancer cells. This study is the first comparative proteomic analysis of basic proteins between the DLD-1 human colon cancer cell line and DLD-1/5-FU its 5-FU resistant sub-line using the radical-free and highly reducing method of twodimensional polyacrylamide gel electrophoresis, which has a superior ability in the separation of basic proteins and the quantification of post-translational modification. A densitometric analysis was performed to quantify the modulated proteins, and protein spots showing significant changes were identified by matrix-assisted laser desorption/ionization timeof-flight/time-of-flight mass spectrometry. Six basic proteins significantly modulated between DLD-1 and DLD-1/5-FU were identified. All of them showed up-regulated expression in DLD-1/5-FU in comparison to DLD-1. The six identified spots, corresponding to five different proteins included heterogeneous nuclear ribonucleoprotein $\mathrm{G}$, mitochondrial trans-
\end{abstract}

Correspondence to: Dr Nobuhiko Tanigawa, Department of General and Gastroenterological Surgery, Osaka Medical College, Osaka, 2-7 Daigaku-machi, Takatsuki City, Osaka 569-8686, Japan

E-mail: sur001@poh.osaka-med.ac.jp

Key words: colon cancer, 5-FU, drug resistance, proteome, RFHR 2-D PAGE cription factor $\mathrm{A}$, histone $\mathrm{H} 2 \mathrm{~B}$, histone $\mathrm{H} 4$ and ribosomal protein L3. Among the 5 basic proteins, several proteins are potentially related to 5 -FU resistance by protecting the cells from DNA damage.

\section{Introduction}

5-Fluorouracil (5-FU) is widely used for the treatment of patients with advanced colon cancers and is still the mainstay of chemotherapy. However, this anticancer effect varies widely among individual patients $(1,2)$. Some patients suffer adverse effects of 5-FU chemotherapy, while others do not. Human colon cancers show heterogeneous behavior at the molecular and cellular levels, and the tumor cells can develop resistance to chemotherapy $(3,4)$. Resistance to 5-FU is one of the most prominent obstacles to successful chemotherapy. Therefore, the identification of the novel biological markers of 5-FU resistance in tumor cells is one of the most important steps for developing optimal treatment strategies. Furthermore, understanding the mechanisms how 5-FU causes tumor cell death and how tumor cells become resistant to 5-FU is an essential step towards predicting or overcoming this resistance.

To identify the predictive biomarkers for 5-FU resistance, several comprehensive studies have investigated 5-FU resistance by DNA microarray analysis technique (5-7). However, the genome is only a carrier of genetic information, whereas the protein is the executor of living activities. Moreover, changes at the mRNA level do not always correlate with alterations in the protein level, and genomics does not analyze the regulation of protein-protein interactions and post-translational modifications that contribute to the protein changes. In this respect, a proteome-based approach that can identify quantitative and qualitative protein changes associated with 5-FU resistance is an important and useful research approach. However, few studies have used 
proteomic-based approach, or specifically, comprehensive proteomics using two-dimensional polyacrylamide gel electrophoresis (2-D PAGE) to screen proteins from human colon cancer cell lines with induced 5-FU resistance $(8,9)$.

In comparative proteomics for identifying novel biomarkers of drug resistance, 2-D PAGE have been performed mainly using an immobilized $\mathrm{pH}$ gradient (IPG) method as the mainstream procedure. Actually, the IPG method can separate proteins within a limited range of isoelectric points, but it can not separate basic proteins with isoelectric points greater than $\mathrm{pH} 10$. On the other hand, with the radical-free and highly reducing (RFHR) 2-D PAGE, the migration rate of protein is determined by the net charge of the protein at $\mathrm{pH} 8.6$ in the first dimension electrophoresis, and the net charge at $\mathrm{pH} 3.6$ and molecular sieving effect in the second dimension electrophoresis. Therefore, separation of proteins in the RFHR 2-D PAGE is not limited by the isoelectric points of protein. Basic proteins, even if the isoelectric points are very high, can be sufficiently separated by the RFHR 2-D PAGE as well as neutral and acidic proteins $(10,11)$. Furthermore, changes of the net charge of proteins by post-translational modification are detected as shifts of protein spots by RFHR 2-D PAGE. This high potential for separation of basic proteins in RFHR 2-D PAGE has been utilized through much of the analysis of the ribosomal proteins (RPs) (11).

5-FU is transformed into two active metabolites, fluorouridine triophosphate (FUTP) and fluorodeoxyuridine monophosphate (FdUMP), and induces tumor cells to undergo apoptosis in response to DNA and RNA damage. FUTP is incorporated into RNA instead of uridine triphosphate, and interferes with the maturation and finally the function of RNA; FdUMP forms a covalent ternary complex with thymidylate synthase (TS) and 5, 10-methylene tetrahydrofolate, thereby inhibiting deoxythymidine monophosphate synthesis from deoxyuridine monophosphate by TS and finally, DNA synthesis (12). Because the basic proteins can bind to DNA/ RNA with a positive protein charge, it may be thought that identification of basic proteins related to DNA and RNA damage by 5-FU, using the RFHR 2-D PAGE, could provide further evidence for elucidation of the 5-FU resistant mechanism in colon cancer cells.

This study is the first comparative proteomic analysis between DLD-1 human colon cancer cell line and its 5-FU resistant line, DLD-1/5-FU, using an improved RFHR 2-D PAGE. An analysis of the enzyme activity analysis associated with 5-FU metabolism indicated that orotate phosphoribosyl transferase (OPRT), a key enzyme of 5-FU anabolism, was lower in DLD-1/5-FU than DLD-1 (13). In the cells with lower OPRT, a decreased metabolism of FUTP from 5-FU induces the attenuation of RNA damage (12). Six basic proteins which were modulated between DLD-1 and DLD-1/5-FU were identified. Among these proteins, several proteins had altered expressions potentially related to resistance to 5-FU induced DNA damage. The identification of the novel biological markers related to 5-FU resistance may therefore greatly help to achieve not only an improvement in both chemotherapeutic regimens and the patient prognosis, but it may also help in the development of novel idea for pharmaceutical products.

\section{Materials and methods}

Tumor cell lines. The human colon cancer cell line, DLD-1 and its 5-FU resistant sub-cell line, DLD-1/5-FU, were used in this study. DLD-1/5FU was selected by stepwise increases in 5-FU concentrations from 0.2 to $100 \mu \mathrm{M}$ (13). Cells were cultured in RPMI-1640 supplemented with $10 \% \mathrm{FBS}$ at $37^{\circ} \mathrm{C}$ with $5 \% \mathrm{CO}_{2}$ in a humidified atmosphere.

In vitro cytotoxicity assay. A colorimetric assay using the tetrazolium salt, 3-(4,5-dimethylthiazol-2-yl)-2,5-diphenyltetrazolium bromide (MTT), was employed to assess the suppression of cell proliferation by $5-\mathrm{FU}$ (provided by Taiho Pharmaceutical) (14). In brief, the cells $\left(5 \times 10^{2}\right.$ cells/well) were seeded into 96-well microplates. After $24 \mathrm{~h}$, the cells were cultured with $200 \mu 1 \mathrm{ZnSO}_{4}$ supplemented in growth medium and treated with varying dosed of 5-FU. At 4 days after exposure to drugs, $0.1 \mathrm{mg}$ of MTT was added to each well and incubated at $37^{\circ} \mathrm{C}$ for an additional $2 \mathrm{~h}$. The plates were centrifuged at $450 \mathrm{x}$ g for $5 \mathrm{~min}$ at room temperature and medium removed. DMSO $(0.15 \mathrm{ml})$ was added to each well to solubilize the crystals and the plates were read at $540 \mathrm{~nm}$ using a microplate reader (Bio-Rad Laboratories Inc.). All experiments were done six times and the mean and $\mathrm{SD}$ of the $\mathrm{IC}_{50}(\mu \mathrm{M})$ values were calculated. The differences of cytotoxic effects of 5-FU were evaluated by the nonparametric Mann-Whitney's U test using Microsoft Office Excel software. The statistical significance was set at Pvalue $<0.05$.

Protein preparation. For protein preparation, 6 sheets of $150 \mathrm{~cm}^{2}$ flask (80\% confluent) of DLD-1 and DLD-1/5-FU were used, respectively. The nuclear, mitochondrial, high salt washed ribosomal and post-ribosomal supernatant fractions were prepared from the cell extract, essentially according to the method of Madjar (15). These fractions were mixed again, and the total proteins were prepared using the acetic acid method (16). After dialysis against $2 \%$ acetic acid at least five times, the proteins were lyophilized and stored at $-80^{\circ} \mathrm{C}$ until use.

2-D PAGE and image analysis. The extracted proteins ( $2 \mathrm{mg} /$ gel) were analyzed by the RFHR 2-D PAGE as previously described with some modifications $(10,11)$. The apparatus for the RFHR procedure was obtained from Nihon Eido (Tokyo, Japan). Briefly, protein samples were dissolved in a lysis buffer containing $10 \mathrm{M}$ urea and $0.2 \mathrm{M} \beta$-mercaptoethanol, and incubated at $37^{\circ} \mathrm{C}$ for $60 \mathrm{~min}$. Pyronine-G (Merck Ltd. Germany) and recrystalized acridine orange (Wako Purified Reagent, Kyoto, Japan) were added to the sample solution as a migration marker for sample charging electrophoresis. After a prerun was performed at $100 \mathrm{~V}$ for $60 \mathrm{~min}$, sample charging electrophoresis was carried out on a $5 \%$ polyacrylamide gel containing $9 \mathrm{M}$ urea, $12 \mathrm{mM} \mathrm{KOH}$ and $0.074 \%$ acetic acid at $100 \mathrm{~V}$ for $30 \mathrm{~min}$. Pyronine-G and acridine orange in the sample solution concentrated rapidly and migrated into the gels, and the sample proteins followed them. When Pyronine-G and acridine orange had run inside the gels for at least $10 \mathrm{~mm}$, the run was finished. Sample gel pieces containing proteins were obtained by cutting the gels 
with a razor at a position immediately below the band of Pyronine-G and within a length of $10 \mathrm{~mm}$. Subsequently, the first dimensional (1-D) separation was performed on a $7 \%$ polyacrylamide gel containing $9 \mathrm{M}$ urea, $400 \mathrm{mM}$ Tris, $500 \mathrm{mM}$ boric acid and $21.5 \mathrm{mM}$ EDTA-2Na. After a prerun was performed at $100 \mathrm{~V}$ for $6 \mathrm{~h}$, the sample gel pieces were inserted into the spaces that were cut out with a ground spatula to the same length as the sample gel pieces. 1-D electrophoresis was performed at $170 \mathrm{~V}$ for $20 \mathrm{~h}$ with air cooling. The second dimensional (2-D) separation was then carried out on a $14 \%$ polyacrylamide gel containing $9 \mathrm{M}$ urea, $50 \mathrm{mM}$ $\mathrm{KOH}$ and $5 \%$ acetic acid $(16 \times 16 \times 0.2 \mathrm{~cm})$. After a prerun was performed at $100 \mathrm{~V}$ for $15 \mathrm{~h}$, the 1-D gels and the sample gels were put on the 2-D gels. The 2-D electrophoresis was performed at $100 \mathrm{~V}$ for $20 \mathrm{~h}$ with air cooling. Gels were stained with Coomassie Brilliant Blue (CBB) G-250 (Nacalai Tesque, Kyoto, Japan). The gels were scanned with a GS-800 Calibrated Densitometer for differential analysis, using PDQuest ${ }^{\mathrm{TM}}$ version 7.1. software (Bio-Rad Laboratories Inc.). In addition the gel images were analyzed by the Quantity One ${ }^{\mathrm{TM}}$ version 4.5.0. software program (Bio-Rad Laboratories Inc.). For each gel, spot detection, area calculation and background subtraction was done, and unmodulated spots on each gel (identified as Elongation factor 1- $\alpha 1$, Gene name EF1A1 in Swiss-Prot) were used as internal controls. The detection of changes in protein maps between the two cell lines was confirmed by visual inspection. The spots were considered significantly up- (or down-) regulated if the corresponding volumes showed an increase (or decrease) by a factor of at least two. For each of the cell lines, 3 lysates (from 3 independent cultures) were analyzed in duplicate (i.e., six experiments for each cell line).

In-gel digestion. The protein spots of interest were excised for digestion with sequence-grade modified trypsin (Promega) or lysyl endopeptidase Lys-C (Wako Purified Reagent) using the following procedures. The gel pieces were destained by incubation in $25 \mathrm{mM}$ ammonium bicarbonate, $30 \%$ methanol for $10 \mathrm{~min}$. For reductive alkylation, gels dehydrated with $100 \%$ acetonitrile for $10 \mathrm{~min}$ at room temperature were incubated for $45 \mathrm{~min}$ at $55^{\circ} \mathrm{C}$ in $50 \mu 1$ of $10 \mathrm{mM}$ dithiothreitol, $25 \mathrm{mM}$ ammonium bicarbonate, followed by replacement of the dithiothreitol solution with $50 \mu 1$ of $50 \mathrm{mM}$ iodoacetamide, $25 \mathrm{mM}$ ammonium bicarbonate and incubation for $30 \mathrm{~min}$ at room temperature in the dark. Gel pieces were washed with $5 \%$ acetic acid, 50\% methanol, dehydrated in $100 \%$ acetonitrile and completely dried in a SpeedVac device. Dried pieces were rehydrated for $30 \mathrm{~min}$ at $4^{\circ} \mathrm{C}$ in $8-20 \mu 1$ of a solution of $50 \mathrm{mM}$ ammonium bicarbonate containing 50-100 ng of trypsin or Lys-C. After incubation for $16 \mathrm{~h}$ at $37^{\circ} \mathrm{C}$, peptides were extracted with $0.1 \%$ trifluoroacetic acid in $30 \%$ acetonitrile for $10 \mathrm{~min}$ at room temperature with sonication. The second extraction of the peptides was performed with $0.1 \%$ trifluoroacetic acid in $60 \%$ acetonitrile. The extracts were concentrated and desalted using ZipTip C18 micropipette tips (Millipore Corp.).

Protein identification by mass spectrometry. For identification using the peptide mass fingerprinting (PMF) method, $0.7 \mu 1$ aliquots were deposited on a target plate (Bruker

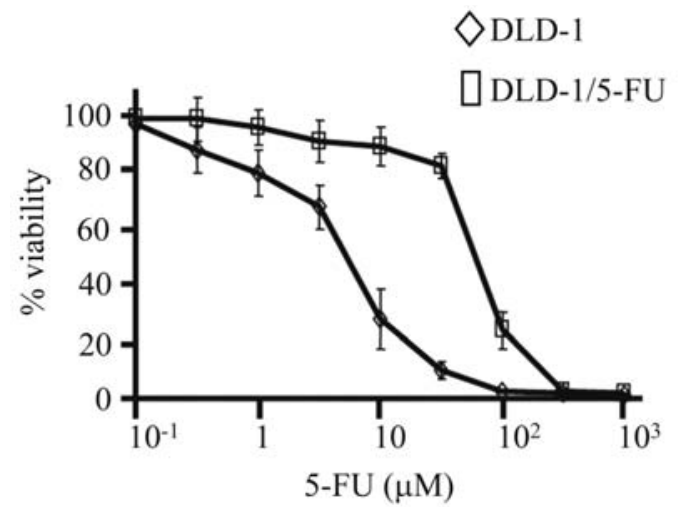

Figure 1. DLD-1 and DLD-1/5-FU drug sensitivities. DLD-1 and DLD-1/ 5-FU were exposed to varying concentrations of 5-FU for 4 days. Growth inhibition was determined by incubation with the tetrazolium dye MTT and by measurement of absorbance at $540 \mathrm{~nm}$. The data represent the means and $\mathrm{SD}$ of six replicates at each concentration.

Daltonik GmbH, Bremen, Germany) followed by deposition of $0.7 \mu 1$ of matrix $(10 \mathrm{mg} / \mathrm{ml} \alpha$-cyano-4-hydroxycinnamic acid in $50 \%$ acetonitrile and $0.1 \%$ trifluoroacetic acid). The identification of each protein was carried out by PMF analysis using a matrix-assisted laser desorption/ionization time-offlight (MALDI-TOF) mass spectrometry (MS) and by tandem mass spectrometry (MS/MS) analysis using Ultraflex (Bruker Daltonik $\mathrm{GmbH}$ ). The proteins were identified by matching the PMF results with the Swiss-Prot protein database using the Mascot Search engine. Database searches were carried out using the following parameters: taxonomy, homo sapiens; enzyme, trypsin or $\mathrm{LysC}$; and allowance of one missed cleavage. Carbamidomethylation was selected as a fixed modification and oxidation of methionine was allowed to be variable. The peptide and fragment mass tolerance were set at $100 \mathrm{ppm}$ and $0.5 \mathrm{Da}$, respectively.

\section{Results}

Cytotoxic effects by 5-FU treatment in human colon cancer cell lines. The cytotoxic effects of 5-FU were determined in DLD-1 and DLD-1/5-FU. Following in vitro treatment of the cells with 5-FU with several different drug concentrations for 4 days, cell proliferation was evaluated using the MTT assay, and the dose-response curves were plotted (Fig. 1). The degree of resistance to 5-FU was estimated at the ratio of the $\mathrm{IC}_{50}$, the concentration inhibiting growth by $50 \%$, of the resistant line and to that of its parent line. The $\mathrm{IC}_{50}$ values of 5-FU were 7.02 $\pm 1.0 \mu \mathrm{M}$ and 74.1 $\pm 4.7 \mu \mathrm{M}$ in DLD-1 cells and DLD-1/5-FU cells, respectively. The cytotoxic effects of 5-FU against the 5-FU resistant line was 10.6-fold lower than that against the parental cells $\left(\mathrm{P}<0.3 \times 10^{-6}\right)$ (Table I). The degree of resistance to $5-\mathrm{FU}$ of the resistant line seems to be quite stable because the $\mathrm{IC}_{50}$ was consistent even after sequential passages without 5-FU (data not shown).

Separation of proteins by RFHR 2-D PAGE. To analyze the underlying mechanisms and identify downstream mediators that are unique to the effects of 5-FU resistance in colon cancer cells, a comparative proteome analysis of the two cell 
Table I. Cytotoxic effect of 5-FU for human colon cancer cell line (DLD-1) and 5-FU resistant cell line (DLD-1/5-FU).

\begin{tabular}{lcc}
\hline Cell lines & $\mathrm{IC}_{50}(\mu \mathrm{M})^{\mathrm{a}}$ for 5-FU & Relative resistance \\
\hline DLD-1 & $7.02 \pm 1.02$ & 10.56 \\
DLD-1/5-FU & $74.14 \pm 4.71$ & \\
\hline
\end{tabular}

${ }^{\mathrm{a}} \mathrm{IC}_{50}$ is defined as the drug concentration that produced a $50 \%$ reduction in 540-nm absorbance compared with untreated controls in MTT assays. ${ }^{\mathrm{b}}$ Fold changes in 5-FU IC $\mathrm{IC}_{50}$ in resistant cells compared with parent cells. lines was conducted. In each cell line, the basic proteins were separated by RFHR 2-D PAGE with high reproducibility. The analytical CBB staining was performed for the detection of differentially expressed basic proteins for each cell line. Typical separations of basic proteins isolated from DLD-1 and DLD-1/5-FU are shown in Fig. 2. In this figure, all of the proteins that have been significantly detected as modulated proteins by the densitometric analysis with confirmed by visual inspectional from each 3 lysates were marked with arrows. To identify the differentially expressed basic proteins, 6 proteins that showed significant changes were chosen, and
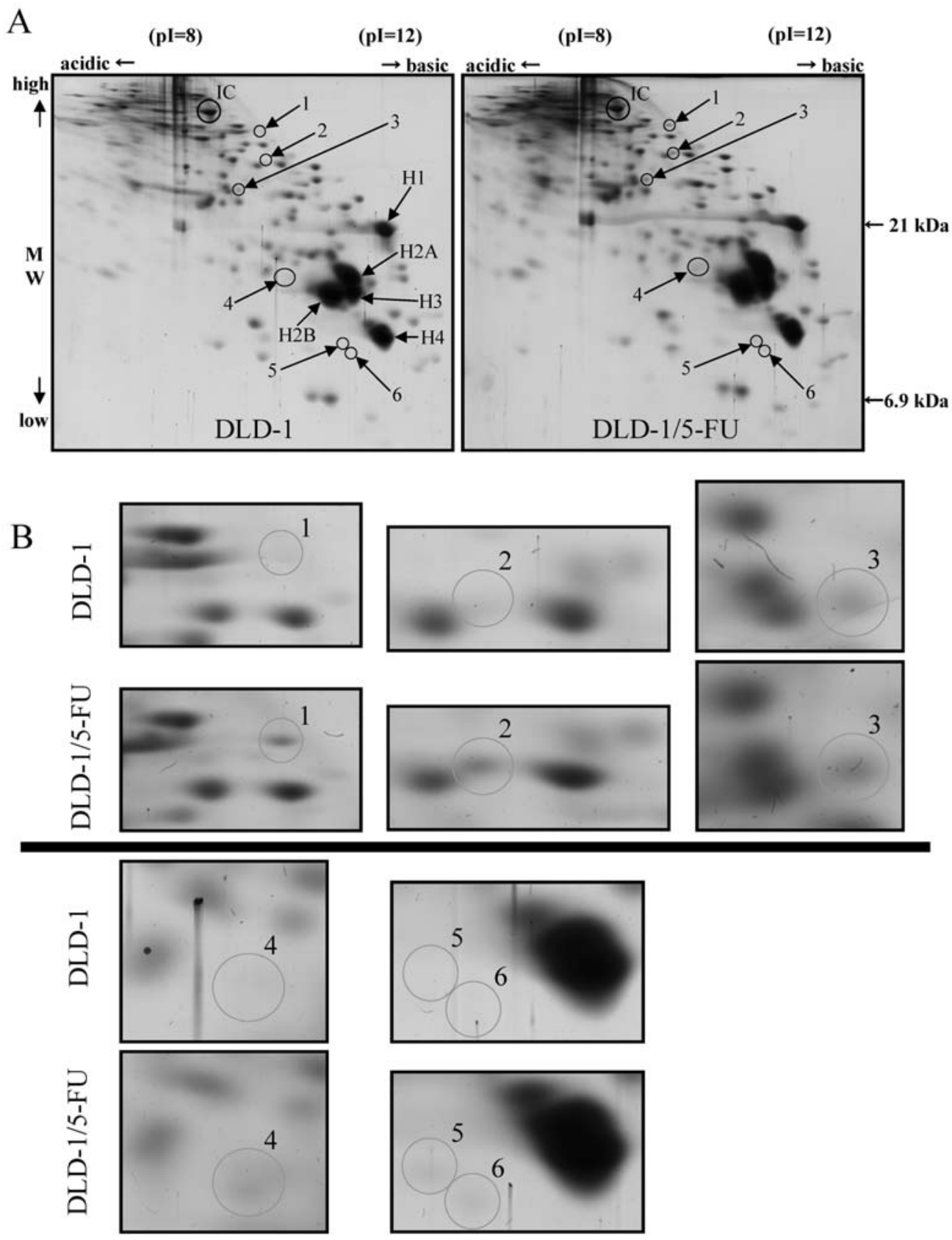

Figure 2. RFHR 2-D PAGE maps of DLD-1 and DLD-1/5-FU. Proteins were separated and visualized by CBB staining. Protein spots marked on the maps were considered differentially expressed and identified by Ultraflex MALDI TOF/TOF MS. Elongation factor 1- $\alpha 1$ was used as an internal control (IC) for normalization purposes. Each cell line from 3 independent cultures was analyzed in duplicate. (A) The arrows and circles indicate the modulated expression of basic proteins between DLD-1 and DLD-1/5-FU. H1, H2A, H2B, H3 and H4 indicate histone H1, histone H2A, histone H2B, histone H3 and histone H4, respectively. All of significantly modulated spots showed up-regulated expression in DLD-1/5-FU in comparison to DLD-1. (B) Magnification of the spots containing the modulated expression. The corresponding identities are listed in Table II. 
Table II. MALDI-TOF/TOF MS identification of the modulated expression of basic proteins in DLD-1/5-FU.

\begin{tabular}{|c|c|c|c|c|c|c|c|c|}
\hline $\begin{array}{l}\text { Spot } \\
\text { no. }\end{array}$ & Identification & $\begin{array}{l}\text { Gene } \\
\text { name }\end{array}$ & $\begin{array}{l}\text { Mass } \\
(\mathrm{Da})\end{array}$ & $\mathrm{pI}$ & $\begin{array}{l}\% \text { Sequence } \\
\text { coverage }^{\mathrm{a}}\end{array}$ & $\begin{array}{l}\text { Msocot } \\
\text { score }^{\mathrm{b}}\end{array}$ & Function & $\begin{array}{l}\text { Change } \\
\text { factor }^{\mathrm{c}}\end{array}$ \\
\hline 1 & Ribosomal protein L3 & RL3 & 46,109 & 10.20 & $\begin{array}{c}39 \\
983.517(10-18)\end{array}$ & 144 & $60 \mathrm{~S}$ ribosomal protein & 2.54 \\
\hline 2 & $\begin{array}{l}\text { Heterogeneous nuclear } \\
\text { ribonucleoprotein } \mathrm{G}\end{array}$ & HNRPG & 42,306 & 10.06 & $\begin{array}{c}47 \\
1,513.660(233-244)\end{array}$ & 242 & Nucleic acid binding protein & 3.15 \\
\hline 3 & $\begin{array}{l}\text { Transcription factor } \mathrm{A} \text {, } \\
\text { mt precursor }\end{array}$ & TFAM & 29,306 & 9.74 & $\begin{array}{c}70 \\
1,171.619(160-169)\end{array}$ & 267 & $\begin{array}{l}\text { Maintenance and replication of } \\
\text { mtDNA }\end{array}$ & 2.37 \\
\hline 4 & $\begin{array}{l}\text { Histone } \mathrm{H} 2 \mathrm{~B} \mathrm{C} / \mathrm{D} / \mathrm{H} / \\
\mathrm{K} / \mathrm{M} / \mathrm{N} / \mathrm{F}\end{array}$ & $\mathrm{H} 2 \mathrm{~B} 1$ & 13,811 & 10.31 & $\begin{array}{c}44 \\
953.541(101-109)\end{array}$ & 123 & $\begin{array}{l}\text { Necessary for the condensation } \\
\text { of nucleosome }\end{array}$ & 2.3 \\
\hline 5 & Histone H4 & $\mathrm{H} 4$ & 11,360 & 11.36 & $\begin{array}{c}37 \\
1,211.650(93-103)\end{array}$ & 75 & $\begin{array}{l}\text { Necessary for the condensation } \\
\text { of nucleosome }\end{array}$ & 2.42 \\
\hline 6 & Histone H4 & $\mathrm{H} 4$ & 11,360 & 11.36 & $\begin{array}{c}46 \\
1,211.650(93-103) \\
1,734.021(46-60)\end{array}$ & 117 & $\begin{array}{l}\text { Necessary for the condensation } \\
\text { of nucleosome }\end{array}$ & 2.39 \\
\hline
\end{tabular}

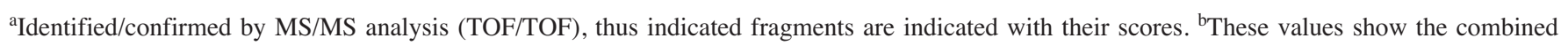
Mascot score, representing the total score of PMF and MS/MS (TOF/TOF) score. ${ }^{~}$ The means calculated from each 3 lysates of DLD-1and DLD-1/5-FU.

all of them showed up-regulated expression in DLD-1/5-FU in comparison to DLD-1 as determined by a spot volume.

Identification of differentially expressed basic proteins between DLD-1 and DLD-1/5-FU. The peptides were extracted from the excised gel after in-gel digestion and then analyzed using Ultraflex MALDI-TOF/TOF MS. The acquired spectra were processed and searched against a Mascot Search engine based on the Swiss-Prot protein database with high confidence based on high scores and sequence coverage. An example [heterogeneous nuclear ribonucleoprotein G (hnRNP G)] of the PMF pattern of a spot and an excised MS/MS pattern obtained by MALDITOF/TOF are shown in Fig. 3. Table II presents these identifications with gene name, theoretical molecular weights, pI, sequence coverage rates, as well as the combined Mascot score that represents the total score of PMF and MS/MS (TOF/TOF) score. These proteins can be classified according to their functions, including RNA splicing proteins (heterogeneous nuclear ribonucleoproteins), mitochondrial DNA replication and maintenance proteins (mitochondrial transcription factor), histones and RPs.

\section{Discussion}

Six spots were identified by MALDI-TOF/TOF MS which were modulated between DLD-1 and DLD-1/5-FU. The five identified proteins included hnRNP G, mitochondrial transcription factor A (TFAM), histone H2B, histone $\mathrm{H} 4$ and RP L3. All of the basic proteins showed up-regulated expression in DLD-1/5-FU in comparison to DLD-1.
The RFHR 2-D PAGE in this study was developed as an improvement of the Kaltschmidt and Wittmann's method with the aim of separating and quantifying proteins that are small, basic and rich in disulphide bridges (17). Extremely small basic proteins are difficult to separate because of their exceedingly high mobility in conventional IPG method. In the RFHR method, the proteins are separated primarily by their net charges at $\mathrm{pH} 8.6$ in $7 \%$ polyacrylamide gels in the first dimension, whereas in the second dimension separation is based mainly on molecular weight and net charge at $\mathrm{pH}$ 3.6 in $14 \%$ polyacrylamide gels. Preruns using radical scavengers were carried out to eliminate residual free radicals from the gels and thereby decreasing the loss of proteins caused by such radicals. The sample charging electrophoresis, before the first dimensional electrophoresis, was also designed to limit protein loss and, in addition, to concentrate a dilute sample solution as a sharp band. The second dimension electrophoresis was carried out at a more acidic $\mathrm{pH} 3.6$ instead of $\mathrm{pH} 4.5$ to obtain a better separation of extremely small basic proteins. In addition, even protein alterations such as post-translational modifications can be clearly separated and quantified $(10,11)$, the RFHR 2-D PAGE protocol has been improved by decreasing the polyacrylamide and increasing the urea concentration of the gels in comparison with the original method, which held the sample loss to a minimum during the sample charging electrophoresis. On the other hand, the total proteins used in the RFHR method were prepared by mixing each fraction after cell fractionation as described in Materials and methods. Some proteins did not migrate in the gel during sample charging electrophoresis because of protein aggregation, and 
A

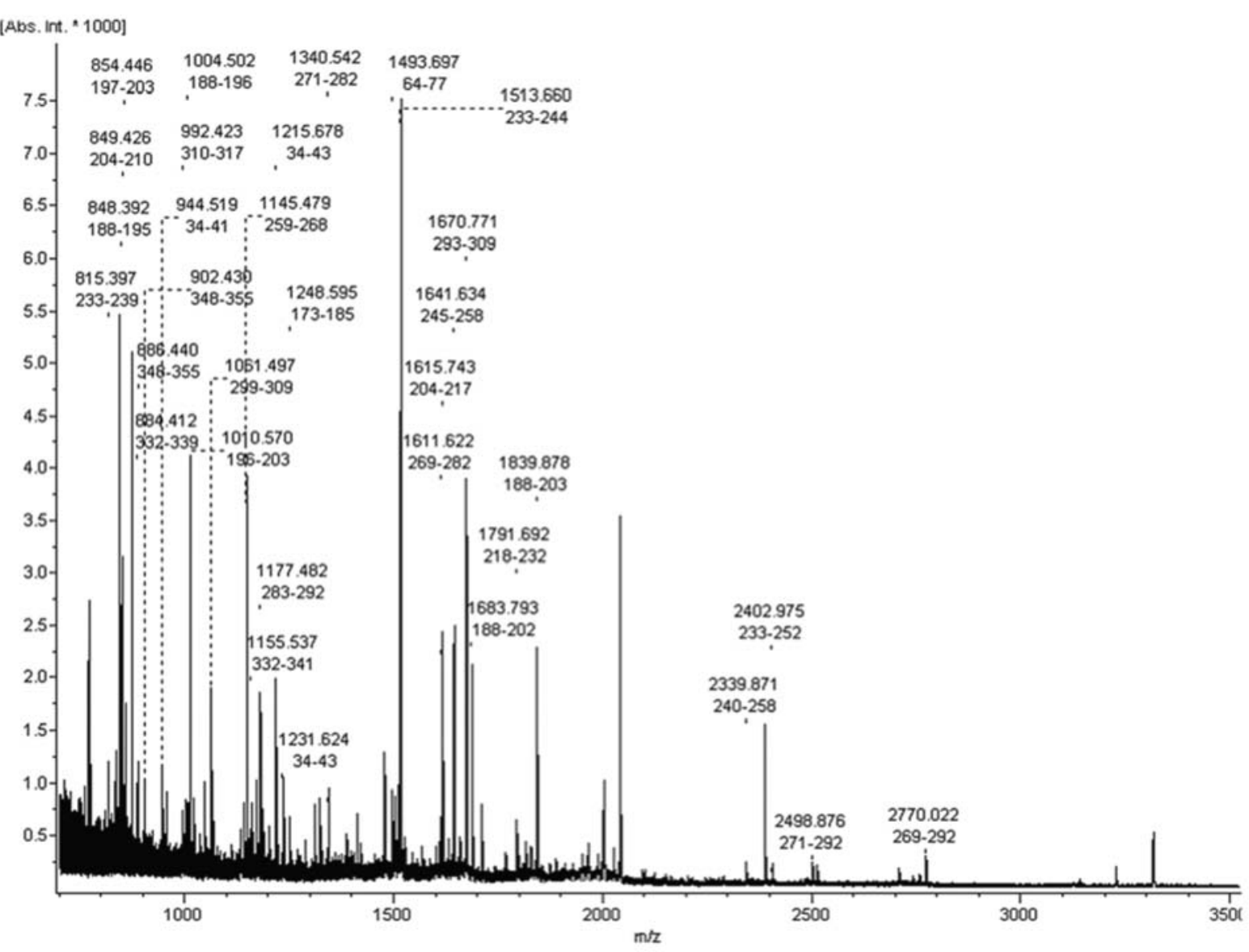

Heterogenous nuclear ribonucleoprotein G

Intensity coverage $56 \%$

Sequence coverage $47 \%$

\begin{tabular}{|c|c|c|c|c|c|c|c|}
\hline 10 & 20 & 30 & 40 & 50 & 60 & 70 & 80 \\
\hline MVE ADRPGKL & FIGGLNTETN & EKALEAVFGK & YGRIVEVLLM & $\begin{array}{l}\text { KDRETNKSRG } \\
\end{array}$ & FAFVTFESPA & D AKD A ARD MN & GKSLDGKA IK \\
\hline 90 & 100 & 110 & 120 & 130 & 140 & 150 & 160 \\
\hline VEQRTKPSFE & SGRRGPPPPP & RSRGPPRGLR & GGRGGSGGTR & GPPSRGGHMD & DGGYSMNFNM & SSSRGPLPVK & RGPPPRSGGP \\
\hline 170 & 180 & 190 & 200 & 210 & 220 & 230 & 240 \\
\hline PPKRSAPSGP & VRSSSGMGGR & APVSRGRDSY & GGPPRREPLP & SRRDVYLSPR & DDGYSTKDSY & SSRDYPSSRD & TRDYAPPPRD \\
\hline 250 & 260 & 270 & 280 & 290 & 300 & 310 & 320 \\
\hline YTYRDYGHSS & SRDDYPSRGY & SDRDGYGRDR & DYSDHPSGGS & YRDSYESYGN & SRSAPPTRGP & PPSYGGSSRY & DDYSSSRDGY \\
\hline & ב & & & & & & \\
\hline 330 & 340 & 350 & 360 & 370 & 380 & 390 & 400 \\
\hline GGSRDSYSSS & RSDLYSSGRD & $\begin{array}{l}\text { RVGRQERGLP } \\
\end{array}$ & $\begin{array}{l}\text { PSMERGYPPP } \\
\end{array}$ & RDSYSSSSRG & APRGGGRGGS & RSDRGGGRSR & $\mathrm{Y}$ \\
\hline
\end{tabular}

Figure 3. (A) An example of identification from the PMF patterns of a spot excised from a 2-D gel

it was recognized that it depended on non-specific proteinprotein interactions among each fraction. To avoid these interactions, the sample preparation method was improved, and this yielded reproducible results.

The results confirmed the lower level of OPRT in DLD-1/ 5-FU in comparison to DLD-1 that had previously been demonstrated by an enzyme activity analysis (13). In addition, TS expression was at the same level and OPRT expression was down-regulated in DLD-1/5-FU in comparison to DLD-1 in Western blot analysis (data not shown). This indicates that the down-regulated expression of OPRT induces 5-FU resistance by avoiding RNA damage, in addition the antitumor action of 5-FU on DLD-1/5-FU may occur mainly via DNA-directed affects. In this study, two basic proteins, hnRNP G and TFAM, associated with DNA damage by 5-FU showed up-regulated expression in DLD-1/5-FU.

hnRNP G belongs to the family of ubiquitously expressed heterogeneous nuclear ribonucleoproteins (hnRNPs). The 
B

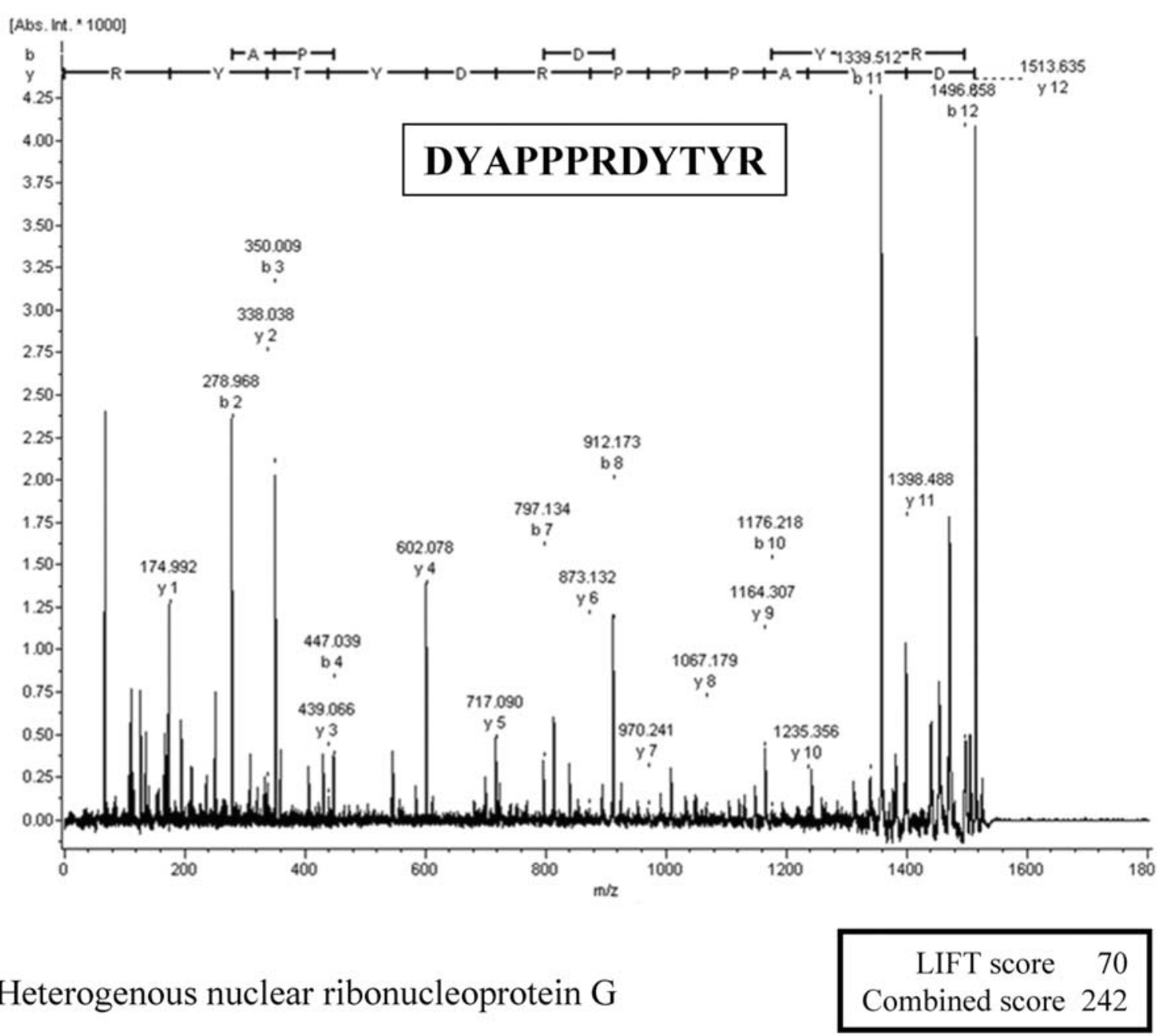

1 MVEADRPGKL FIGGLNTETN EKALEAVFGK YGRIVEVLLM KDRETNKSRG

51 FAFVTFESPA DAKDAARDMN GKSLDGKAIK VEQATKPSFE SGRRGPPPPP

101 RSRGPPRGLR GGRGGSGGTR GPPSRGGHMD DGGYSMNFNM SSSRGPLPVK

151 RGPPPRSGGP PPKRSAPSGP VRSSSGMGGR APVSRGRDSY GGPPRREPLP

201 SRRDVYLSPR DDGYSTKDSY SSRDYPSSRD TADYAPPPRD YTYRDYGHSS

251 SRDDYPSRGY SDRDGYGRDR DYSDHPSGGS YRDSYESYGN SRSAPPTRGP

301 PPSYGGSSRY DDYSSSRDGY GGSRDSYSSS RSDLYSSGRD RVGRQERGLP

351 PSMERGYPPP RDSYSSSSRG APRGGGRGGS RSDRGGGRSR Y

Figure 3. (B) An example of the MS/MS pattern obtained by MALDI TOF/TOF. The result of hnRNP G is shown. The mass peak in the PMF pattern as indicated in (A), 1,513.660, was analyzed by an MS/MS analysis.

hnRNPs constitute a large family of nucleic acid-binding proteins with more than 30 different members. They were first described as chromatin-associated RNA binding proteins with a major role in RNA processing (18). Recent studies showed that the biological functions of hnRNPs are extremely diverse and include RNA turnover, telomere biogenesis, oncogenesis, and spermatogenesis (19). Moreover, the involvement of p53 in the repair of DNA double-strand breaks via a DNA non-homologous end-joining (NHEJ) process, indicate that hnRNP $\mathrm{G}$ is associated with a protein complex with the DNA ends in p53 containing human RKO colorectal cancer cells, but is not associated with the DNA ends with a p53 knockdown based on a DNA end-protection assay. Meanwhile, it was demonstrated that the ectopic expression of hnRNP G significantly enhances the fidelity of DNA NHEJ and the protection of DNA ends in human cancer cells lacking hnRNP G protein or containing mutant hnRNP $\mathrm{G}$ by binding to the DNA ends and protecting them from degradation by nuclease, In addition, the depletion of endogenous hnRNP G notably diminished the fidelity of NHEJ (20). The slower exonuclease activity in the hnRNP G overexpressing cells was attributable to an increased delay 
in the initiation of DNA degradation possibly caused by hnRNP $\mathrm{G}$ binding and protection of the DNA ends against exonuclease activity (20).

TFAM is a member of a high-mobility group (HMG) of proteins named on the basis of their electrophoretic mobility in polyacrylamide gels, and was first cloned as a transcription factor of the mitochondrial DNA. This group is composed of non-histone chromatin proteins and transcription factors that can bind DNA either non-specifically or in a sequencedependant manner (21). TFAM is encoded in the nucleus and is synthesized on cytoplasmic ribosomes as a precursor, which is converted, upon mitochondrial importation, to a mature form. The mature form contains two HMG boxes, HMG-like domain 1 (HMG1) and HMG-like domain 2 (HMG2), joined by a basic 36 amino acid linker and followed by a basic 27 amino acid tail (22). Most of the TFAM proteins have been shown to stimulate transcription of mitochondrial DNA by binding to the D-loop region, and it is thought that TFAM not only contributes to the mitochondrial DNA stability by packaging of the mitochondrial DNA, but also maintains the mitochondrial DNA (23). Recently, it was shown that TFAM preferentially recognizes cisplatin-damaged DNA and oxidized DNA. In addition, increased apoptosis has been observed in cells lacking mitochondrial DNA gene expression, thus suggesting that TFAM is involved in apoptosis because mitochondria act as a pivotal decision center in many types of apoptotic response $(24,25)$. Yoshida et al reported that TFAM expression was up-regulated in mitochondria interacted by p53 after human epidermoid cancer cells (KB cells) were treated with cisplatin. Up-regulated expression of TFAM was recognized in mitochondria when HCT116 colon cancer cell was treated with 5-FU (26). Nuclear HMG-box protein, HMG1, has been shown to be enhanced binding of cisplatin-damaged DNA in association with p53 (27), and cisplatin-damaged DNA binding of TFAM is activated by $\mathrm{p} 53$. Therefore, since in TFAM transfected HeLa cell, the susceptibility of three chemotherapeutic drugs, etoposide, camptothecin and cisplatin, are decreased in comparison to the parental cell line, up-regulated expression of TFAM may contribute to the prevention of chemothepeutic drug-induced apoptosis (28).

The up-regulated expression of hnRNP $G$ and TFAM in DLD-1/5-FU, and the fact that hnRP G is involved in the repair of DNA, and TFAM is engaged in the mitochondrial DNA, indicates that these proteins may possibly be associated with the protection of not only DNA but also mitochondrial DNA from the damage affected by 5-FU and maintain the chemoresistance in this 5-FU resistant cell line. Although hnRNP $G$ and TFAM may possibly be novel candidates for 5-FU resistance in these colon cancer cell lines, the regulation of the translational expression and their association with mechanisms of 5-FU resistance must be fully characterized.

Over 70 RPs must assemble with the rRNAs in the nucleolus to form the small and large ribosomal subunits (40S and 60S, respectively). A large number of RPs do not appear to be essential for ribosome function, and their probable task is to enhance the function of the rRNA (29). Currently, scarce data are available on human RP L3, but in plants the silencing of this gene causes alterations in growth, development and ribosome biogenesis (30). Bergqvist et al have shown that the telomerase activity levels were positively correlated with RP L3 gene expression in 10 esophageal carcinoma cell lines by DNA microarray analysis (31). Telomerase is a reverse transcriptase that synthesizes telomeric repeats on chromosomal ends to compensate for telomere shortening during DNA replication (32). Telomerase is repressed in the majority of somatic cells but activated in approximately $85 \%$ of human malignancies (33). Telomerase activity levels are up-regulated during cancer progression in several malignancies, and, in addition, inhibition of telomerase activity can increase chemosensitivity (34).

Histones, including core histones and linker histones, are highly basic proteins, and maintain chromatin structures in an electrically neutral state, since DNA is acidic. Two molecules of each of the 4 core histone types (H2A, H2B, H3 and H4) interact to form a histone octamer. DNA is coiled around this octamer, which forms a nucleosome, considered to be the minimum and basic structure of chromatin (35). In contrast, histone $\mathrm{H} 1$, a linker histone, normally binds to the linker DNA between nucleosomes, sealing off two turns of DNA around a histone octamer, and is involved in gene activation, since these areas easily accessible to transcription factors (35). Recently, it has become clear that these core histone $\mathrm{N}$-terminal tails can be post-translationally modified by processes such as acetylation, methylation, phosphorylation, ubiquitination and sumoylation, that target specific amino acid residues $(36,37)$, and gene regulation is controlled by epigenetic modifications that define the chromatin state, mainly via histone modification. It appears that each histone octamer is uniquely modified according to different combinations of post-translational modifications. ATP-dependent chromatin remodeling complexes are primarily responsible for the rearrangement of nucleosomal arrays, according to signals defined by histone modifications $(38,39)$. The sliding of histone octamers, around which DNA is coiled, is facilitated by ATP-dependent chromatin remodeling complexes, thereby exposing new naked DNA regions. The best characterized of the histone modifications is histone acetylation and deacetylation. Co-regulator complexes with histone acetyltransferase activate the transcription of target genes through the acetylation of histones, while histone deacetyltransferase complexes deacetylate histones and serve as co-repressors $(38,39)$. Histone methylation is also induced by co-regulator complexes. Furthermore, histone phosphorylation is conspicuously observed in cells that undergo DNA damage or apoptosis introduced by UV-irradiation and chemotherapeutic drugs (40). Three protein spots were identified as histone $\mathrm{H} 2 \mathrm{~B}$ and $\mathrm{H} 4$ among the up-regulated proteins expressed in DLD-1/5-FU by MALDI-TOF/TOF MS (Fig. 2). However, these up-regulated spots on the 2-D gel were located on the acidic side of the histone clusters. This may have been the result of post-translational modification of $\mathrm{H} 2 \mathrm{~B}$ and H4. In other words, through the parts of these histones underwent post-translational modification such as the acetylation of lysine/threonine residues or the phosphorylation of serine residues. Changes in the protein net charge by post-translational modifications are detected as shifts of protein spots by RFHR 2-D PAGE (11), and this is one of the greatest advantages of separation and quantification of posttranslational forms in RFHR 2-D PAGE. Nevertheless, it is 
thought that some genes that control the 5-FU resistant mechanism are constantly up-regulated in DLD-1/5-FU, and further research is therefore necessary to identify how the gene expression is affected as a result of these post-translational modifications of histone $\mathrm{H} 2 \mathrm{~B}$ and $\mathrm{H} 4$.

In conclusion, this study demonstrated the high reproducibility of basic protein maps of colon cancer cell lines by RFHR 2-D PAGE. The 5-FU resistant line and its parent cell lines clearly differed regarding in their protein expression profile. Five basic proteins which were modulated between DLD-1 and DLD-1/5-FU were identified. Among them, several proteins were associated with 5-FU pharmacologic DNA damage in tumor cells, and may potentially be associated with the biological basis of 5-FU resistance. These proteomic approaches may not only be a powerful tool that can lead to the identification of novel potential markers involved in 5-FU resistance of colon cancer cells, but also be useful in completing the understanding of these complex mechanisms. Moreover, these observations will facilitate the development of novel therapeutic strategies against colon cancer.

\section{Acknowledgements}

This study was supported in part by a grant-in-aid for Science Research from Japan Society for the Promotion of Science.

\section{References}

1. Miwa M, Ura M, Nishida M, Sawada N, Ishikawa T, Mori K, Shimma N, Umeda I and Ishitsuka H: Design of a novel oral fluoropyrimidine carbamate, capecitabine, which generates 5fluorouracil selectively in tumours by enzymes concentrated in human liver and cancer tissue. Eur J Cancer 34: 1274-1281, 1998.

2. Rich TA, Shepard RC and Mosley ST: Four decades of continuing innovation with fluorouracil: current and future approaches to fluorouracil chemoradiation therapy. J Clin Oncol 22: 2214-2232, 2004.

3. Chau I and Cunningham D: Chemotherapy in colorectal cancer: new options and new challenges. Br Med Bull 64: 159-180, 2002.

4. Royce ME, Medgyesy D, Zukowski TH, Dwivedy S, Hoff PM and Pazdur R: Colorectal cancer: chemotherapy treatment overview. Oncology 14: 40-46, 2000.

5. Zembutsu H, Ohnishi Y, Tsunoda T, Furukawa Y, Katagiri T, Ueyama Y, Tamaoki N, Nomura T, Kitahara O, Yanagawa R, Hirata $\mathrm{K}$ and Nakamura Y: Genome-wide cDNA microarray screening to correlate gene expression profiles with sensitivity of 85 human caner xenografts to anticancer drugs. Cancer Res 62: 518-527, 2002.

6. Kihara C, Tsunoda T, Tanaka T, Yamana H, Furukawa Y, Ono K, Kitahara O, Zembutsu H, Yanagawa R, Hirata K, Takagi T and Nakamura Y: Prediction of sensitivity of esophageal tumors to adjuvant chemotherapy by cDNA microarray analysis of geneexpression profiles. Cancer Res 61: 6474-6479, 2001.

7. Kang HC, Kim IJ, Park JH, Shin Y, Ku JL, Jung MS, Yoo BC, Kim HK and Park JG: Identification of genes with differential expression in acquired drug-resistant gastric cancer cells using high-density oligonucleotide microarrays. Clin Cancer Res 10: 272-284, 2004.

8. Yoo BC, Jeon E, Hong SH, Shin YK, Chang HJ and Park JG: Metabotropic glutamate receptor 4-mediated 5-Fluorouracil resistance in a human colon cancer cell line. Clin Cancer Res 10: 4176-4184, 2004.

9. Shin YK, Yoo BC, Chang HJ, Jeon E, Hong SH, Jung MS, Lim SJ and Park JG: Down-regulation of mitochondrial F1F0ATP synthase in human colon cancer cells with induced 5fluorouracil resistance. Cancer Res 65: 3162-3170, 2005.
10. Wada A: Analysis of Escherichia coli ribosomal proteins by an improved two dimensional gel electrophoresis. I. Detection of four new proteins. J Biochem 100: 1583-1594, 1986.

11. Wada A: Analysis of Escherichia coli ribosomal proteins by an improved two dimensional gel electrophoresis. II. Characterization of four new proteins. J Biochem 100: 1595-1605, 1986.

12. Longley DB, Harkin DP and Johnston PG: 5-fluorouracil: mechanisms of action and clinical strategies. Nat Rev Cancer 3: 330-338, 2003.

13. Murakami Y, Kazuno H, Emura T, Tsujimoto H, Suzuki N and Fukushima M: Different mechanisms of acquired resistance to fluorinated pyrimidines in human colorectal cancer cells. Int $\mathrm{J}$ Oncol 17: 277-283, 2000.

14. Carmichael J, De Graff WG, Gazdar AF, Minna JD and Mitchell JB: Evaluation of tetrazolium-based semiautomated colorimetric assay: assesment of chemosensitivity testing. Cancer Res 47: 936-942, 1987.

15. Madjar JJ: Preparation of ribosomes and ribosomal proteins from cultured cells. In: Cell Biology. Celis JE (ed). Academic Press Inc., San Diego, pp657-661, 1994.

16. Hardy SJ, Kurland CG, Voynow P and Mora G: The ribosomal proteins of Escherichia coli. I. Purification of the $30 \mathrm{~S}$ ribosomal proteins. Biochemistry 8: 2897-28905, 1969.

17. Kaltschmidt E and Wittmann HG: Ribosomal proteins. VII. Two-dimensional polyacrylamide gel electrophoresis for fingerprinting of ribosomal proteins. Anal Biochem 36: 401-412, 1970.

18. Dreyfuss G, Matunis MJ, Piuol-Roma S and Burd CG: hnRNP proteins and the biogenesis of mRNA. Annu Rev Biochem 62: 289-321, 1993.

19. Krecic AM and Swanson MS: hnRNP complexes: composition, structure, and function. Curr Opin Cell Biol 11: 363-371, 1999.

20. Shin KH, Kim RH, Kang MK, Kim RH, Kim SG, Lim PK, Yochim JM, Baluda MA and Park NH: p53 promotes the fidelity of DNA end-joining activity by, in part, enhancing the expression of heterogeneous nuclear ribonucleoprotein G. DNA Repair 6: 830-840, 2007.

21. Bustin M: Regulation of DNA-dependent activities by the functional mofifs of the high-mobility-group chromosomal proteins. Mol Cell Biol 19: 5237-5246, 1999.

22. Reyes A, Mezzina M and Gadaleta G: Human mitochondrial transcription factor A (mtTFA): gene structure and characterization of related pseudogenes. Gene 291: 223-232, 2002.

23. Larsson NG, Wang J, Wilhelmsson H, Oldfors A, Rustin P, Lewandoski M, Barsh GS and Clayton DA: Mitochondrial transcription factor $\mathrm{A}$ is necessary for mtDNA maintenance and embryogenesis in mice. Nat Genet 18: 231-236, 1998.

24. Wang J, Silva JP, Gustafsson CM, Rustin P and Larsson NG: Increased in vivo apoptosis in cells lacking mitochondrial DNA gene expression. Proc Natl Acad Sci USA 98: 4038-4043, 2001 .

25. Green DR and Reed JC: Mitochondria and apoptosis. Science 281: 1309-1312, 1998.

26. Yoshida Y, Izumi H, Torigoe $\mathrm{T}$, Ishiguchi H, Itoh H, Kang D and Kohno K: P53 physically interacts with mitochondrial transcription factor $\mathrm{A}$ and differentially regulates binding to damaged DNA. Cancer Res 63: 3729-3734, 2003.

27. Imamura T, Izumi H, Nagatani G, Ise T, Nomoto M, Iwamoto $Y$ and Kohno K: Interaction with p53 enhances binding of cisplatin-modified DNA by high mobility group 1 protein. J Biol Chem 276: 7534-7540, 2001.

28. Pastukh V, Shokolenko I, Wang B, Wilson G and Alexeyev M: Human mitochondrial transcription factor A possesses multiple subcellular targeting signals. FEBS J 274: 6488-6499, 2007.

29. Ruggero D and Pandolfi PP: Does the ribosome translate cancer? Nat Rev Cancer 3: 179-192, 2003.

30. Popescu SC and Tumer NE: Silencing of ribosomal protein L3 genes in $\mathrm{N}$. tabacum reveals coordinate expression and significant alterations in plant growth, development and ribosome biogenesis. Plant J 39: 29-44, 2004

31. Bergqvist M, Brattström D, Brodin D, Lindkvist A, DahlmanWright K, Dreilich M, Wagenius G and Paulsson-Karlsson Y: Genes associated with telomerase activity levels in esophageal carcinoma cell lines. Dis Esophagus 19: 20-23, 2006.

32. Lingner J, Cooper JP and Cech TR: Telomerase and DNA end replication: no longer a lagging strand problem? Science 269: 1533-1534, 1995. 
33. Dhaene K, van Marck E and Parwaresch R: Telomeres, telomerase and cancer: an up-date. Virchows Arch 437: 1-16, 2000.

34. Shay JW, Zou Y, Hiyama E and Wright WE: Telomerase and cancer. Hum Mol Genet 10: 677-685, 2001.

35. Kishimoto M, Fujiki R, Takezawa S, Sasaki Y, Nakamura T, Yamaoka K, Kitagawa H and Kato S: Nuclear receptor mediated gene regulation through chromatin remodeling and histone modifications. Endocr J 53: 157-172, 2006.

36. Jenuwein T and Allis CD: Translating the histone code. Science 293: 1074-1080, 2001

37. Fischle W, Wang Y and Allis CD: Binary switches and modification cassettes in histone biology and beyond. Nature 425: 475-479, 2003.
38. McKenna NJ and O'Malley BW: Combinatorial control of gene expression by nuclear receptors and coregulators. Cell 108: 465-474, 2002.

39. Rachez C, Lemon BD, Suldan Z, Bromleigh V, Gamble M, Näär AM, Erdjument-Bromage H, Tempst P and Freedman LP: Ligand-dependent transcription activation by nuclear receptors requires the DRIP complex. Nature 398: 824-828, 1999.

40. Fernandez-Capetillo O, Allis CD and Nussenzweig A: Phosphorylation of histone $\mathrm{H} 2 \mathrm{~B}$ at DNA double-strand breaks. J Exp Med 199: 1671-1677, 2004. 